\title{
Development and Application of the 3D Model Test System for Water and Mud Inrush of Water-Rich Fault Fracture Zone in Deep Tunnels
}

\author{
Yanhui Guo $\mathbb{D}^{1},{ }^{1}$ Zhijun Kong, ${ }^{2}$ Jin $\mathrm{He}^{2}$ and Ming Yan $^{1}$ \\ ${ }^{1}$ Faculty of Public Safety and Emergency Management, Kunming University of Science and Technology, Kunming 650093, China \\ ${ }^{2}$ College of Civil and Architectural Engineering, Yunnan Agricultural University, Kunming 650201, China
}

Correspondence should be addressed to Yanhui Guo; guoyanhui0818@kust.edu.cn

Received 12 August 2021; Accepted 15 September 2021; Published 4 October 2021

Academic Editor: Gan Feng

Copyright (c) 2021 Yanhui Guo et al. This is an open access article distributed under the Creative Commons Attribution License, which permits unrestricted use, distribution, and reproduction in any medium, provided the original work is properly cited.

In order to study the evolution process, damage characteristics, and occurrence mechanism of water and mud inrush disaster in deep tunnel fault zone with infiltration instability under complex conditions, a set of the three-dimensional physical model test systems of water and mud inrush flow-solid coupling in tunnel fault zones is developed. The system mainly comprises a rigid test frame, ground stress loading system, hydraulic loading system, multiple information monitoring and acquisition system, and mud and water protrusion recovery system. The system's main features are that it can meet the model's simulation of the ground stress field, water pressure, and other complex environments subjected to ground stress, and water pressure gradients can be controlled. The system is characterized by high rigidity, high-pressure strength, visualization, good sealing, and expandability. Taking the water fault zone of a well in the Dazhu Mountain Tunnel of the Darui Railway as the research object, the new fault zone and surrounding rock similar materials applicable to the flow-solid coupling model test are designed using the self-developed flowsolid coupling similar materials. The system is used for model tests to reveal the spatial and temporal changes of the surrounding rock stress field and seepage field during the tunnel excavation process. The test results show that the system is stable and reliable, and the research method and results are of guiding significance to the research of the same type of underground engineering.

\section{Introduction}

In recent years, China has developed into a country with the most significant number of tunnels and underground projects, the enormous scale, the most complex geological conditions, and the most diverse structural forms in the world [1-3]. More and more transportation infrastructure projects are shifting to the western mountainous and karst areas with a more complex topography and geological conditions. Tunnel construction faces new challenges, such as considerable buried depth, high ground stress, strong karst, high-water pressure, and complex structures [4-7], resulting in frequent disasters during the construction process. Statistics show that nearly $80 \%$ of traffic, water conservancy, and hydropower projects have experienced water and mud inrush disasters during the construction or operation. As a result, nearly $90 \%$ of the tunnels have been postponed or even forced to be suspended or rerouted, especially in areas with solid karst and high-water pressure; frequent geological disasters such as tunnel water bursting and mud bursting have brought great difficulties to construction, causing heavy casualties and economic losses [8-10].

Because of the main problems of high ground stress and high-water pressure in the construction of karst tunnels, it is essential to master the spatial and temporal changes of the surrounding rock stress field, displacement field, and seepage field during the tunnel excavation in such complex geological conditions to effectively prevent water and mud burst disasters and improve the stability of the tunnel surrounding rock. Due to the complexity of such tunnels' surrounding rock structure and environment, we should adopt various means to study them as far as possible, and the main research methods are theoretical analysis, numerical 
calculation, and model test [11-17]. However, theoretical analysis has many limitations in dealing with nonlinear and discontinuous problems of complex rock masses. In contrast, numerical analysis methods cannot accurately portray the mechanical properties of the surrounding rock masses in terms of intrinsic model and calculation parameters selection and have inherent deficiencies in simulating the engineering response under complex conditions [18-20]. The geomechanical model test makes up for the shortage of theoretical analysis and numerical simulation. It can systematically and comprehensively reflect the characteristics of the surrounding rock and its spatial relationship with karst pipes and caves, more accurately simulate the tunnel excavation process, and visually reflect the physical and mechanical phenomena of the deep rock mass, which is a proven research tool $[21,22]$.

At present, the relevant research on geomechanical model test system device mainly includes the following: Zhu et al. [23] developed an extensive accurate triaxial loading geomechanical model test system, which can carry out horizontal lateral step load under entire triaxial stress state and successfully observe the fracture phenomenon and fracture process of surrounding rock of caverns with different large buried depths, which is helpful to the study of fracture mechanism; Zhang et al. [24] developed a model test system for water and mud inrush in fault fracture zone and studied the catastrophic evolution process and failure characteristics of water and mud inrush in tunnel during fault exposure; Li et al. [25-28] developed a new fluidstructure coupling model test system, which can be used for plane stress and plane strain model tests, and revealed the variation laws of surrounding rock displacement field, seepage field, and tunnel wall pressure during tunnel excavation; Li et al. [29, 30] developed a three-dimensional model test system for water inrush geological disasters in deep and long tunnels and obtained the minimum water separation safety thickness under different engineering conditions; Zhang [31] developed an ultrahigh-pressure 3D loading model test system with intelligent numerical control function, which revealed the collapse failure mode, nonlinear deformation characteristics, and stress change law of ancient karst cave formation. To sum up, there is a relative lack of geomechanical model tests related to water and mud inrush disasters in tunnels in fault fracture zones. There are mainly the following problems to be solved when using the above model test system to study water and mud inrush disasters in fault fracture zones: (1) The model size is small, it is impossible to carry out large-scale tests, and there is an apparent boundary effect. (2) Most of them focus on the stability of surrounding rock during tunnel excavation under the action of in situ stress, without considering the catastrophic evolution process of rock mass in fault fracture zone under the combined action of groundwater and excavation disturbance. (3) There are few studies on similar materials of filling medium in the fault fracture zone. At present, most of the fluid-solid coupling similar materials only consider physical indexes such as density and size, and few similar materials meet solid mechanical properties and permeability [32-35]. Less similar materials with different characteristics of surrounding rock and fault rock are applied to the same test simultaneously.

The test system of this study is mainly composed of a rigid test frame, in situ stress loading system, hydraulic loading system, multivariate information monitoring and acquisition system, and mud and water protrusions recovery system. The system's main feature is that it can meet the model's simulation of the complex environment such as in situ stress field and water pressure. The in situ stress and water pressure gradient are controllable. The system has significant stiffness, high bearing strength, visualization, good sealing, and strong expansibility. Taking the Yijingshui fracture zone of the Dazhu Mountain Tunnel of Darui railway as the research object, using the self-developed fluidstructure coupling similar material, a new fault fracture zone and surrounding rock that are suitable for fluid-structure coupling model test are designed in this paper. The system is used for model tests to reveal the surrounding rock stress field's temporal and spatial variation laws and seepage field during tunnel excavation.

\section{Development of a 3D Model Test System for Water and Mud Inrush in Tunnel Fault Fracture Zones}

The model test system is mainly composed of a rigid test frame, a ground stress loading system, a hydraulic loading system, a muddy water protrusion recovery system, and multiple information monitoring and acquisition systems. The test system has the advantages of significant stiffness, visualization, easy operation, and wide application. It can realize the study of the disaster mechanism of water inrush and mud inrush through tunnel monitoring data collection and multi-information analysis at each stage of the test process.

2.1. Model Rigid Test Stand. Figure 1 is the main body of the model rigid test frame. The test frame is seamlessly welded by a $1.2 \mathrm{~cm}$ thick steel plate, and the base is made of an I-beam of $0.5 \mathrm{~cm}$ thickness. Small holes are evenly opened on the brackets on both sides of the box to play a role in fixing and adjusting the height of the reaction frame. Other structures such as plexiglass and stiffened rib plates on the front and back sides of the box are connected by flanges, while waterproof treatment is done around.

In the experiment, the function of the pressure uniformly distributed plate is mainly to convert the concentrated force exerted by the jack on the plate into a uniformly distributed force and apply it to similar materials. The pressure uniform plate is designed with double handles, with a length of $98 \mathrm{~cm}$ and a width of $47 \mathrm{~cm}$, which are slightly smaller than the internal dimensions of the test frame, which facilitates the lead-out of the sensor wires and water supply pipes. The design of the reaction force frame is $100 \mathrm{~cm}$ in length, $30 \mathrm{~cm}$ in width, and $15 \mathrm{~cm}$ in height. It is fixed on the test frame, and the position can be adjusted flexibly. 


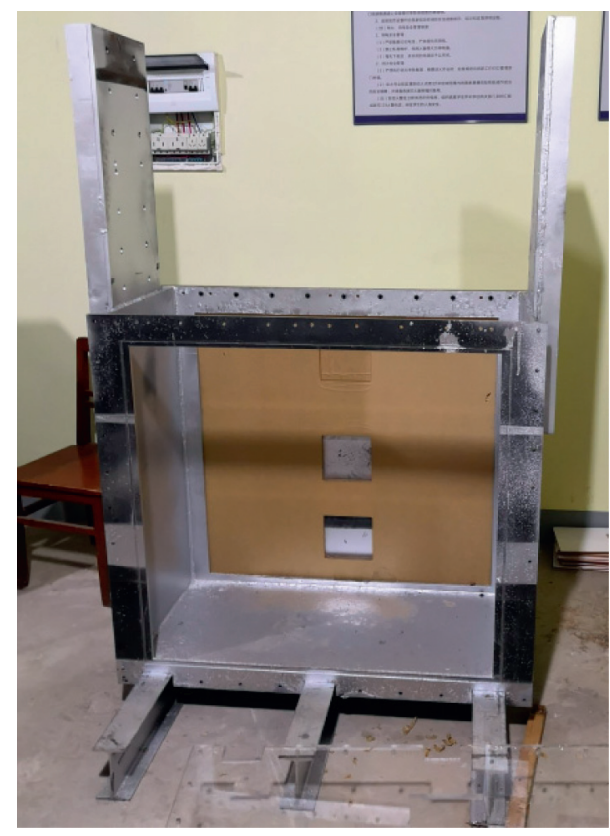

Figure 1: Main structure of the test frame.

2.2. Ground Stress Loading System. The ground stress loading system is composed of a separated hydraulic jack, hydraulic pump, pressure gauge, etc. Before system assembly, the in situ stress to be supplemented by the loading system shall be determined according to the geometric similarity ratio, stress similarity ratio, simulated surrounding rock bulk density, and actual buried depth of the test model. Combined with the area of the bearing area of the model, the real force to be applied can be calculated, and the measuring range of the jack top can be determined on this basis. Considering that the subsequent simulation test of water and mud inrush disaster, the movable position of reaction frame, and the filling height of materials during the test may be carried out for the deeper buried tunnel, the tonnage of separated hydraulic jack is $20 \mathrm{t}$, the stroke of piston rod is $10 \mathrm{~cm}$, and the inner diameter of oil cylinder is $6.4 \mathrm{~cm}$. The conversion relationship between supplementary in situ stress and pressure gauge reading is as follows [36, 37]:

$$
\sigma_{1}=\frac{\sigma_{2} S}{10.24 \pi} \text {. }
$$

Among them, $\sigma_{1}$ is the pressure gauge reading; $\sigma_{2}$ is the ground stress to be added to the test; and $S$ is the area of the model pressure zone.

2.3. Water Pressure Loading System. The hydraulic loading system is mainly composed of a gas-liquid composite constant pressure water tank, a high-pressure nitrogen cylinder, and auxiliary equipment, as shown in Figure 2. The constant pressure water tank is made of stainless steel and can withstand a pressure of $0.3 \mathrm{MPa}$. There are three holes on the top of the water tank: the water inlet, the air inlet, and the pressure gauge interface. The bottom of the water tank is the water outlet. The air inlet of the water tank is connected to a high-pressure nitrogen cylinder through a hose, and the water outlet is connected to a water outlet through a rubber tube with an inner diameter of $12 \mathrm{~mm}$ to provide water for the model. The volume of the high-pressure nitrogen cylinder is $40 \mathrm{~L}$, and the gas pressure in the bottle is about $13 \mathrm{MPa}$. In order to meet the pressure required by the test, a pressure-reducing valve is arranged at the gas outlet to reduce the output pressure in the bottle, thereby providing a stable air pressure source.

\subsection{Multivariate Information Monitoring and Acquisition} System. The multi-information monitoring and acquisition system includes monitoring components and data acquisition systems. The monitoring components used in the test mainly include micro earth pressure box, pore water pressure sensor, displacement meter, high-definition filming instruments, and others, which monitor the signals of surrounding rock stress, pore water pressure, displacement, and macro process of surrounding rock from fracture generation to water and mud emergence through the tunnel excavation process and hydraulic loading process, respectively. The earth pressure cell used for monitoring is a DMTY earth pressure cell, with a measuring range of $500 \mathrm{kPa}$, a specification of $28 \times 10 \mathrm{~mm}$, a sensitivity coefficient of $0.256 \sim 0.270 \mathrm{kPa} / \mu \varepsilon$, a full bridge connection, and a bridge resistance of $350 \Omega$. The self-contained line includes two power lines. Moreover, two signal lines can work in the water-saturated medium. The element for monitoring pore water pressure is the DMKY pore water pressure sensor produced by the same company, with a range of $200 \mathrm{kPa}$, a specification of $32 \times 15 \mathrm{~mm}$, and a sensitivity coefficient of $0.100 \sim 0.106 \mathrm{kPa} / \mu \varepsilon$. Working at $120 \%$ of the rated range, the miniature sensor used in the test is shown in Figure 3.

The data acquisition system includes strain gauges and data acquisition software, as shown in Figure 4. According to the number of embedded sensors, select the XL2118A24 static resistance strain gauge. This model has 24 data acquisition channels, measuring stress, strain, force, and other physical quantities. The operating mode of the instrument has two kinds of automatic control of the machine and external control of the computer. When using external computer control, as long as the USB connection line equipped with the instrument is used to connect the strain gauge with the computer equipped with this type of data acquisition software and set the sensor's parameters, the real-time data acquisition can be realized.

2.5. Muddy Water Protrusion Material Recovery System. The mud and water protrusion recovery system includes a $0.2 \mathrm{~mm}$ diameter cylindrical filter sieve, a water sealing ring, a $0.03 \mathrm{~mm}$ diameter cylindrical filter sieve, a transparent plastic panel, a water storage container, a capacity scale plate, a wheel bracket, a positioning scale, and a water outlet. The water seal ring is set at the connection of each layer of filter sieve, the transparent plastic panel is installed on the sidewall of the cylindrical filter sieve with $0.03 \mathrm{~mm}$ particle size, and the bottom of the water storage container is rounded. The 


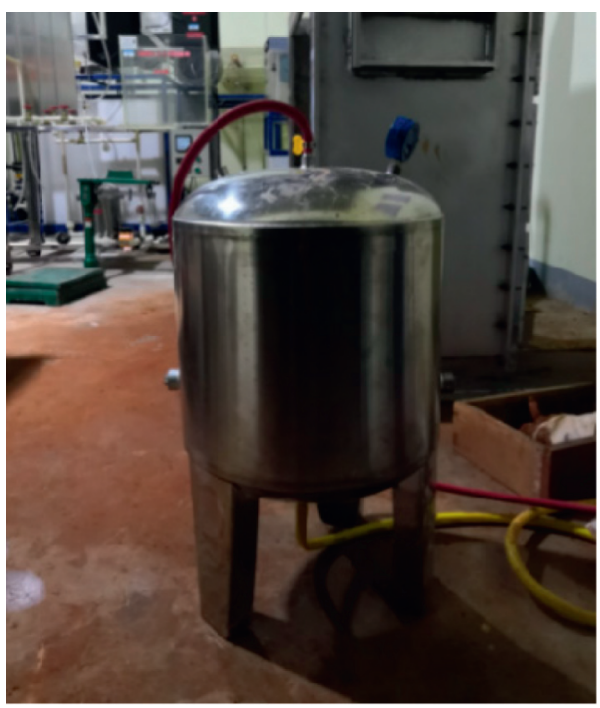

(a)

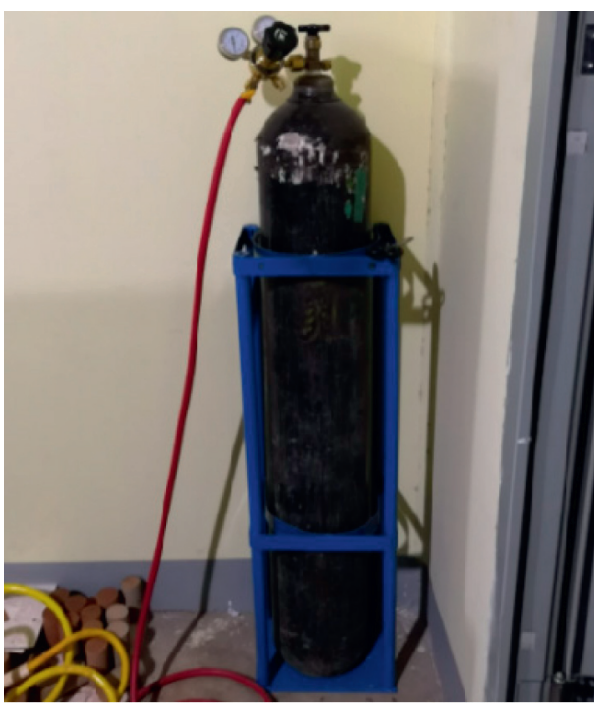

(b)

FIGURE 2: Gas-liquid composite constant pressure water tank and high-pressure nitrogen cylinder. (a) Constant pressure water tank. (b) High-pressure nitrogen cylinder.

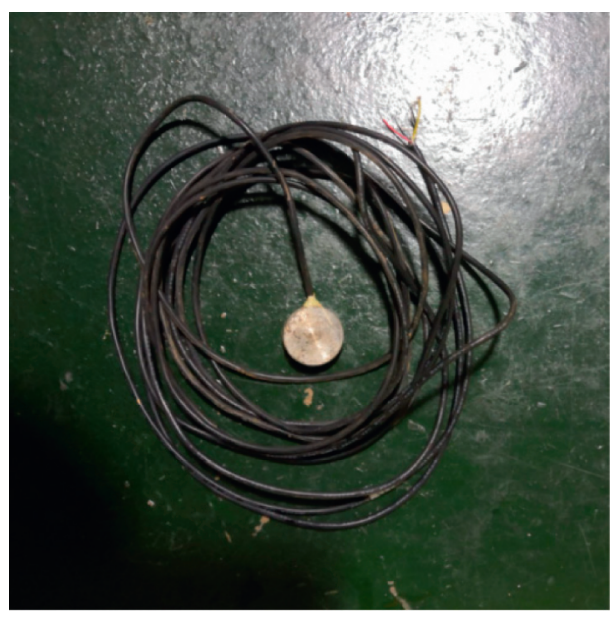

(a)

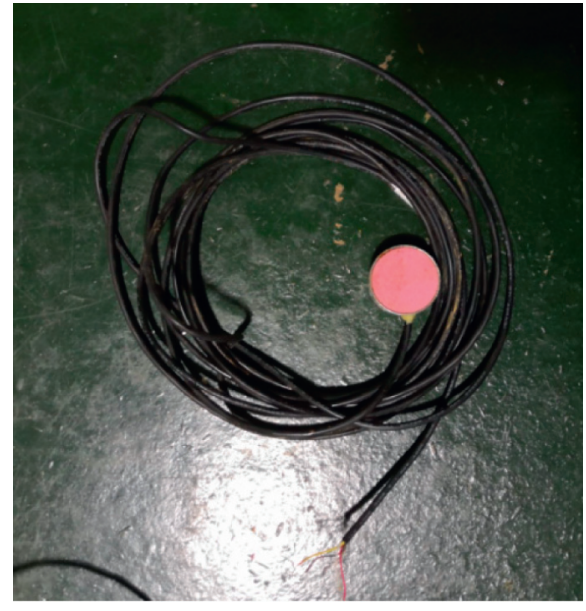

(b)

Figure 3: Microsensor. (a) Earth pressure box. (b) Pore water pressure sensor.

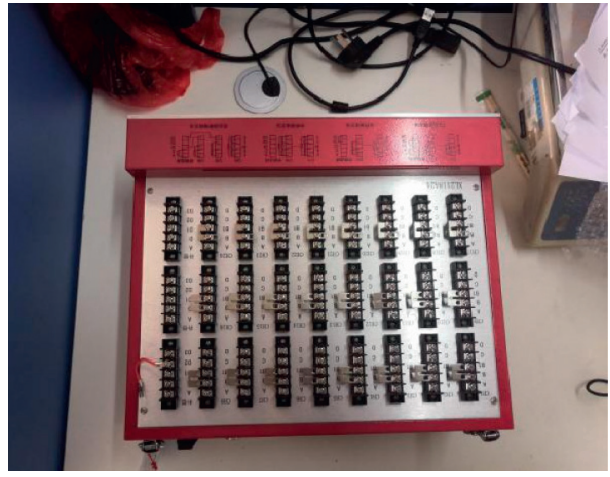

(a)

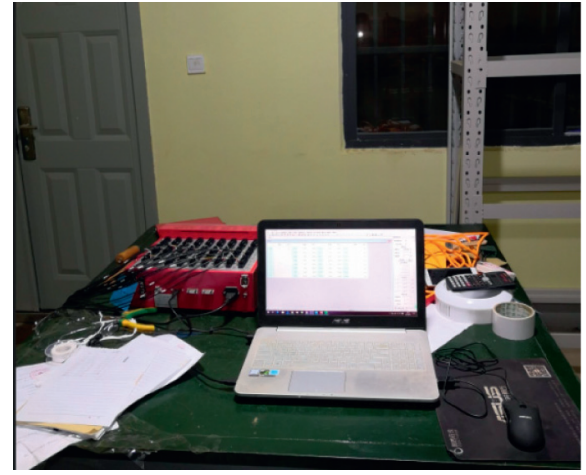

(b)

Figure 4: Data acquisition system. (a) Static resistance strain gauge. (b) Data acquisition instrument. 
capacity scale plate is located on the sidewall of the water storage container, and the water outlet is installed at the lowest point of the water storage container. The retractable wheel bracket is located at the bottom of the water storage container, and the positioning scale can adjust the level and height of the mud and water protrusion recovery system.

The tunnel water and mud inrush fluid-solid coupling $3 \mathrm{D}$ visualization physical model test system is shown in Figure 5.

\section{Model Test of Water and Mud Inrush in the Tunnel Fault Fracture Zone}

3.1. Project Overview. The Dazhu Mountain Tunnel of the Darui Railway is located in Baoshan City, Yunnan Province, crossing the southern section of the famous Hengduan Mountains in western Yunnan Province, starting and ending at mileage D2K110 + 524 D2K125 + 008, with a total length of $14484 \mathrm{~m}$, of which $13803 \mathrm{~m}$ is the length of the single tunnel line main cavern; $680 \mathrm{~m}$ is the large span section area; and the maximum depth of the tunnel is $995 \mathrm{~m}$. The longitudinal slope of the tunnel is designed as a small "man" character slope, except for the exit section $2750 \mathrm{~m}$ for 3\% uphill, other sections of the maximum longitudinal slope of $23.5 \%$, and the overall terrain north high south low.

As shown in Figure 6, the tunnel's area has a complex geological environment and well-developed fault structures. It has traversed six faults, including Wulishao, Yanzi's Nest, Shuizhai, Yijingshui Fault, Shiguandi Fault, and Banjiazhai as well as the Jinjiashan syncline, and there are threefold structures including Yangjiashan inverted anticline and five karst areas. The Dazhu Mountain Tunnel is rich in groundwater. According to the relationship between the excavated water volume and the designed water volume of the revealed section, it is estimated that the maximum water inflow of the tunnel can reach three times the original design, that is, $360000 \mathrm{~m}^{3} / \mathrm{d}$. Since the start of the Dazhu Mountain Tunnel, the tunnel has suffered deep water and mud inrush disasters, with about 200 million $\mathrm{m}^{3}$ of water gushing, which is equivalent to 15 West Lakes. This paper chooses the IV grade weak surrounding rock, which accounts for about $30 \%$ of the main tunnel of the Dazhu Mountain Tunnel, as the prototype of the similar model test surrounding rock, and the geometric dimensions of the excavation section (width 6.16 and height $9.41 \mathrm{~m}$ ) of the surrounding rock of the tunnel are used as the model, a prototype of excavation section size.

3.2. Fluid-Structure Coupling Similarity Theory. When conducting similar model tests, the model and prototype should be made to satisfy similar geometry, dynamics, and physics relationships between materials or media [38]. However, due to the objective conditions, it is impossible to achieve complete similarity between the model and the prototype, and it is often necessary to perform a similar transformation of the model.

The ratio of the same physical quantity between the prototype $(P)$ and the model $(M)$ in the similar model test is

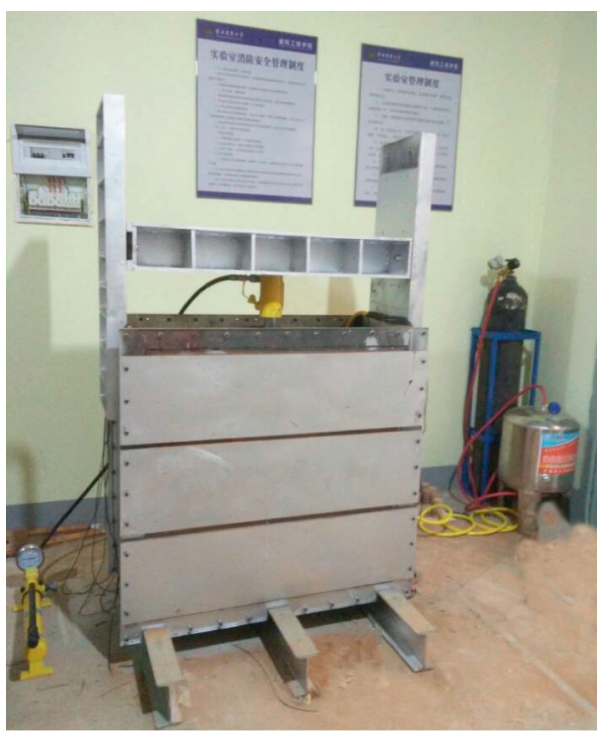

Figure 5: Tunnel water and mud inrush fluid-solid coupling 3D visualization physical model test system.

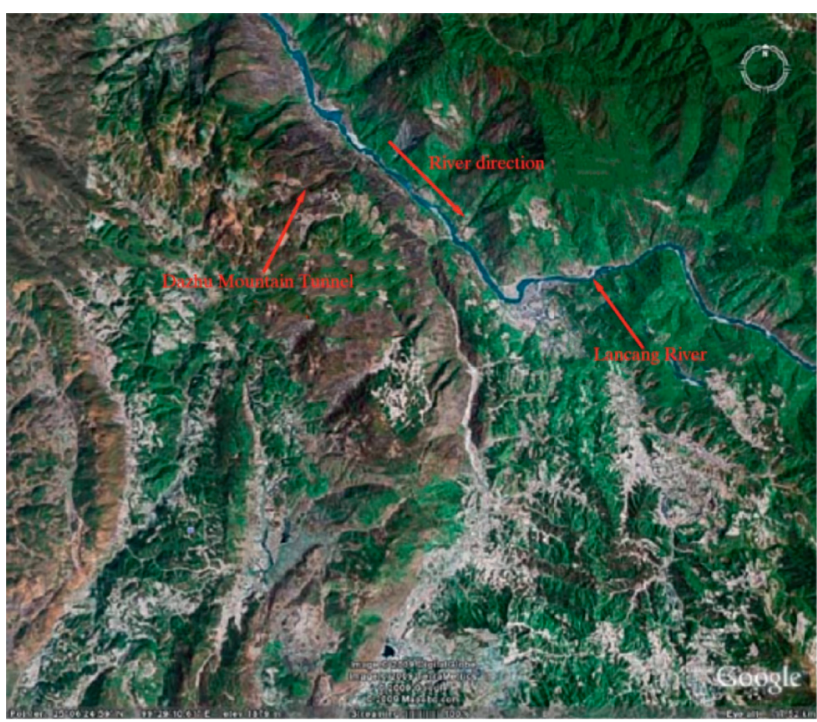

FIgUre 6: Topographic map of the Dazhu Mountain Tunnel.

called the similarity ratio $(C)$, and the mathematical expression between the three is [39]

$$
C_{x}=\frac{X_{P}}{X_{M}}
$$

$X$ is the similar physical quantities, including geometry $l$, capacitance $\gamma$, stress $\sigma$, compressive strength $\sigma_{c}$, tensile strength $\sigma_{t}$, strain $\varepsilon$, cohesion $c$, internal friction angle $\psi$, Poisson's ratio $\mu$, and permeability coefficient $k$.

According to the similarity theory of fluid-solid coupling, the mathematical model of fluid-solid coupling in continuous media is used, and the seepage equation, equilibrium equation, and effective stress equation can be expressed as follows [40-42]. 
Seepage equation is

$$
K_{x} \frac{\partial^{2} p}{\partial^{2} x}+K \frac{\partial^{2} p}{\partial^{2} y}+K \frac{\partial^{2} p}{\partial^{2} z}=S \frac{\partial p}{\partial t}+\frac{\partial e}{\partial t}+W
$$

Equilibrium equation is

$$
\sigma_{i j, i}+X_{j}=\rho \frac{\partial^{2} u_{i}}{\partial t^{2}}
$$

Effective stress equation is

$$
\sigma_{i j}=\overline{\sigma_{i j}}+\alpha \delta p
$$

where $K_{x}, K_{y}$, and $K_{z}$ are the permeability coefficients in the $x, y$, and $z$ directions, respectively; $P$ is the water pressure; $S$ is the water storage coefficient; $e$ is the volume strain; $W$ is the source-sink term; $\sigma_{i j}$ is the total stress tensor; $\overline{\sigma_{i j}}$ is the effective stress tensor; $X_{j}$ is the volume force; $\rho$ is the density; $\alpha$ is the bolt effective stress coefficient; and $\delta$ is the Kronecker notation.

Assume that the similarity ratio of each parameter of the prototype $(P)$ and the model $(M)$ is

$$
\left\{\begin{array}{l}
G_{P}=C_{G} G_{M} ; E_{P}=C_{E} E_{M} ; x_{P}=C_{x} x_{M}, \\
\lambda_{P}=C_{\lambda} \lambda_{M} ; e_{P}=C_{e} e_{M} ; U_{P}=C_{U} U_{M}, \\
X_{P}=C_{X} X_{M} ; \rho_{P}=C_{\rho} \rho_{M} ; t_{P}=C_{t} t_{M} .
\end{array}\right.
$$

From equation (6),

$$
\left\{\begin{array}{l}
\frac{\partial e_{P}}{\partial x_{P}}=\frac{C_{e}}{C_{x}} \frac{\partial e_{M}}{\partial x_{M}} \\
\nabla^{2} u_{P}=\frac{C_{u} \nabla^{2} u_{M}}{C_{x}^{2}} \\
\frac{\partial^{2} u_{P}}{\partial t_{P}^{2}}=\frac{C_{u}}{C_{t}^{2}} \frac{\partial u_{P}}{\partial t_{M}^{2}}
\end{array}\right.
$$

Combining equation (3) with its geometric equation and physical equation, the equation containing only the displacement component is obtained as

$$
\left\{\begin{array}{l}
G \nabla^{2} u+(\lambda+G) \frac{\partial e}{\partial x}+X=\rho \frac{\partial^{2} u}{\partial t^{2}} \\
G \nabla^{2} v+(\lambda+G) \frac{\partial e}{\partial y}+Y=\rho \frac{\partial^{2} v}{\partial t^{2}} \\
G \nabla^{2} w+(\lambda+G) \frac{\partial e}{\partial z}+Z=\rho \frac{\partial^{2} w}{\partial t^{2}}
\end{array}\right.
$$

where $\nabla^{2}=\partial^{2} / \partial x^{2}+\partial^{2} / \partial y^{2}+\partial^{2} / \partial z^{2}$ is the Laplace operator symbol; $\lambda=\mu E /[(1+\mu)(1-2 \mu)]$ is the Lamé constant; $E$ is the modulus of elasticity; $\mu$ is the Poisson ratio; $G=E /(2$ $(1+\mu))$ is the shear modulus of elasticity; $e=\partial / \partial x^{2}$ $+\partial / \partial y^{2}+\partial / \partial z^{2}$ is the volume strain; and $X, Y$, and $Z$ are the volume forces in the $x, y$ and $z$ directions, respectively.
It can be obtained by formulas (6)-(8):

$$
C_{G} \frac{C_{u}}{C_{x}^{2}}=C_{\lambda} \frac{C_{e}}{C_{x}}=C_{G} \frac{C_{e}}{C_{x}}=C_{X}=C_{\rho} \frac{C_{u}}{C_{t}^{2}},
$$

where $C_{G}$ is the shear elastic modulus similar ratio, $C_{u}$ is the displacement similar ratio, $C_{x}$ is the geometric similar ratio, $C_{\lambda}$ is the Lamé constant similar ratio, $C_{e}$ is the volume strain similar ratio, $C_{X}$ is the volume weight similar ratio, $C_{\rho}$ is the density similar ratio, and $C_{t}$ is the time similar ratio.

According to seepage equation (3), considering that the similar test material is a uniform continuous medium, let $K_{x}=K_{y}=K_{z}=K$ and introduce the function

$$
\left\{\begin{array}{l}
K_{P}=C_{K} K_{M}, \\
K_{S}=C_{S} S_{M} ; Q_{P}=C_{Q} Q_{M} \\
y_{P}=C_{y} y_{M} ; z_{P}=C_{z} z_{M}
\end{array}\right.
$$

Here, $C_{x}=C_{y}=C_{z}=C$; substituting formula (10), then

$$
\frac{C_{K} C_{P}}{C_{x}^{2}}=\frac{C_{K} C_{P}}{C_{y}^{2}}=\frac{C_{K} C_{P}}{C_{z}^{2}}=\frac{C_{S} C_{P}}{C_{t}}=\frac{C_{e}}{C_{t}}=C_{w} .
$$

Here, $C_{P}$ is the water pressure similarity ratio, $C_{t}$ is the time similarity ratio, and $C_{w}$ is the source-sink term similarity ratio.

Because $C_{e}=1, C_{P}=C_{\gamma} C_{l}, C_{t}=\sqrt{C_{l}}$, and $C_{l}=C_{x}=C_{y}=C_{z}$, it can be deduced that the source and sink terms are similar $C_{w}=1 / \sqrt{C_{l}}$, the water storage coefficient is similar $C_{S}=1 /\left(C_{\gamma} \sqrt{C_{l}}\right)$, and the permeability coefficient is similar $C_{K}=\sqrt{C_{l}} / C_{\gamma}$.

3.3. Model Test Similarity Ratio. The geometric similarity ratio is $C_{l}=80$ selected according to the size of the test frame of the tunnel water and mud inrush model test system, the peak pressure provided by the loading system, and the actual situation of the model test object. The bulk density similarity ratio is $C_{\gamma}=1.2$ as the primary similarity ratio, and the prototype and model can be derived from the similarity theory. The other physical and mechanical parameters and hydraulic property parameters are similar to the following examples:

Dimensionless similarity (Poisson's ratio, strain, and internal friction angle): $C_{\mu}=C_{\varepsilon}=C=1$.

Similarity ratio of elastic modulus, stress, strength, and cohesion: $C_{E}=C_{\sigma}=C_{R}=C_{c}=C_{\gamma} C_{l}=96$.

Permeability coefficient similarity ratio: $C_{K}=\sqrt{C_{l}} /$ $C_{\gamma}=7.45$.

3.4. Proportioning Selection of Similar Materials for FluidSolid Coupling in the Model Test. Taking the Dazhu Mountain Tunnel Engineering of the Darui Railway as the research background, a large amount of grade IV weak surrounding rock and the corresponding excavation section size existing in the tunnel construction are used as the basis of the model test. According to the physical and mechanical parameters of the grade IV surrounding rock in the study area, combining fluid-solid coupling similarity theory and 
model test research, the similarity ratios of physical and mechanical parameters and hydraulic properties of similar materials are obtained, and the parameters of surrounding rock under ideal conditions are obtained, as shown in Table 1.

According to the test results of similar material parameters of each ratio and the ideal material, comparison can be obtained from the best ratio of similar materials for the surrounding rock of the tunnel water and mud inrush model test. The finalized similar material ratio is shown in Table 2. When the content of red clay is $6.35 \%$, that is, the ratio of mountain sand: red clay: cement: water is equal to $12: 0.95: 0.7: 1.3$, the physical and mechanical parameters and hydraulic properties of similar materials in the surrounding rock are close to those of the similar ideal materials; specifically, the material capacity is between the ideal material capacity, while the material compressive strength and permeability coefficient differ from the similar ideal materials in the range of $1.01 \% \sim 2.46 \%$. The difference between the compressive strength and permeability coefficient of the material and the similar ideal material ranges from $1.01 \%$ to $2.46 \%$, indicating that the ratio of similar material can better meet the requirements of the surrounding rock material in the model test. A similar material of fault zone was selected as the solution with the lowest permeability coefficient among the ratios, that is, $1: 1: 0.4$ for red clay: sand: gravel, and the material permeability coefficient was $5.39 \times 10^{-4} \mathrm{~cm} / \mathrm{s}$.

3.5. The Overall Plan Design of the Experiment. According to the geometric similarity ratio of the model test and the size of the excavation section of the prototype, the model test tunnel has a section width of $7.7 \mathrm{~cm}$ and a height of $11.76 \mathrm{~cm}$. The interlaced distance between the filling fault and the tunnel designed by the experiment is twice the hole diameter, the interlacing angle is $60^{\circ}$, the fault thickness is $12.5 \mathrm{~cm}$, and the inclined extension length is $18.75 \mathrm{~cm}$. The corresponding actual thickness and length are $10 \mathrm{~m}$ and $15 \mathrm{~m}$, respectively, buried in the upper part of the fault. The water outlet device provides stable water pressure for the fault and is used to simulate the high-pressure and water-rich faults encountered in tunnel construction. The test simulates the buried depth of the tunnel $500 \mathrm{~m}$, and the filling height of similar materials in the rigid test box is about $92 \mathrm{~cm}$, which is $40 \mathrm{~cm}$ higher than the tunnel vault. Since the ground stress provided by the filling material does not meet the requirements of the model test, additional supplements must be made through the ground stress loading system. The vertical stress is about $106 \mathrm{kPa}$, and the stress reaches a predetermined value through stepwise loading.

After the in situ stress loading is completed and the material deformation is stable, draw the tunnel excavation contour line at the reserved excavation position using the wooden tunnel section made with a ratio of $1: 1$ and carry out the tunnel excavation. The test adopts the full-section excavation method. Data collection is performed simultaneously as the excavation, and the excavation is stopped after the excavation length reaches $42 \mathrm{~cm}$. Then turn on the water pressure loading system to supply water to the fault. The water pressure loading adopts a step-by-step pressurization method. The initial water pressure is $10 \mathrm{kPa}$, and the subsequent increase is $5 \mathrm{kPa}$ (when the software monitoring data is stable, it can continue to be loaded to the lower water pressure); until the water and mud inrush occurs in the tunnel, the test is deemed to be over.

3.6. Monitoring Arrangement. Using model tests to study the disaster mechanism of tunnel filling-type fault water and mud inrush is mainly realized by analyzing the monitoring data obtained during the test. Before the test, the monitoring section, monitoring points, and corresponding monitoring elements should be selected scientifically and reasonably according to the test purpose and test requirements so that the data collected by the test can accurately and comprehensively reflect the surrounding rock and fault filling during the evolution of the tunnel water and mud inrush. The dynamic change characteristics of objects can also achieve the purpose of reducing monitoring costs.

In order to study the change law of multiple information such as surrounding rock and fault stress and seepage pressure during the model test, the central monitoring components of the test include earth pressure box and pore water pressure sensor. Along the tunnel excavation direction, the test designed a total of 2 monitoring sections, which were set at $1 / 2$ position $(Y=25 \mathrm{~cm})$ and $3 / 4$ position $(Y=29.69 \mathrm{~cm})$ in the direction of fault tendency. Monitoring section 1 has earth pressure boxes and pore water pressure sensors arranged around the tunnel, one time the diameter and two times the tunnel's diameter. The primary function of the earth pressure boxes is to monitor the changes in the surrounding rock stress during tunnel excavation and water pressure loading. The pore water pressure gauge is used to monitor the seepage pressure information of the antioutburst rock mass between the tunnel and the fault. Three earth pressure boxes are arranged on the monitoring section 2, which correspond to the placement of the pore water pressure gauges on the monitoring section 1, which are used to monitor the stress changes of the antioutburst rock mass between the tunnel and the fault. The overall monitoring plan is shown in Figure 7.

3.7. Model Filling. In order to meet the requirements of compactness and uniformity of the model body, this test uses layered filling and layer-by-layer compaction. The model filling process is shown in Figure 8. The specific steps are as follows:

(1) Before filling the materials, embed five prefabricated glass plates into the high-strength plexiglass opening positions at the front and rear of the rigid test frame (excluding the holes at the reserved tunnel excavation positions), and contact the plates with the glass. Apply glass glue to seal the part, then wrap the edge of the prefabricated wooden board with doublesided tape, and embed it in the hole at the tunnel excavation position on the plexiglass (for easy removal of the wooden board during excavation). After 
TABLE 1: Surrounding rock prototype and ideal similar material parameters.

\begin{tabular}{lccc}
\hline Material type & Bulk density, $\gamma / \mathrm{kN} / \mathrm{m}^{3}$ & Compressive strength, $\sigma / \mathrm{MPa}$ & Permeability coefficient, $\mathrm{k} / \mathrm{cm} / \mathrm{s}$ \\
\hline Raw rock & $20 \sim 23$ & 38 & $4.23 \times 10^{-4}$ \\
Ideal similar material & $16.67 \sim 19.17$ & 0.396 & $5.68 \times 10^{-5}$ \\
\hline
\end{tabular}

TABLE 2: Ratio and performance parameters of similar materials for surrounding rock.

\begin{tabular}{lccc}
\hline Similar material ratio & Bulk density, $\gamma / \mathrm{kN} / \mathrm{m}^{3}$ & Compressive strength, $\sigma / \mathrm{MPa}$ & Permeability coefficient, $k / \mathrm{cm} / \mathrm{s}$ \\
\hline $12: 0.95: 0.7: 1.3$ & 18.16 & 0.40 & $5.54 \times 10^{-5}$
\end{tabular}

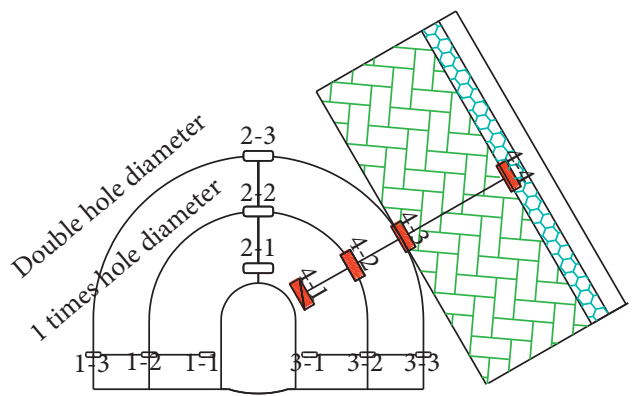

$\square$ Earth pressure cell
$\square$ Pore water pressure gauge
$\square \Delta$ Filling fault
$\square \square$ Gravel sublayer
$\square$ Water outlet device

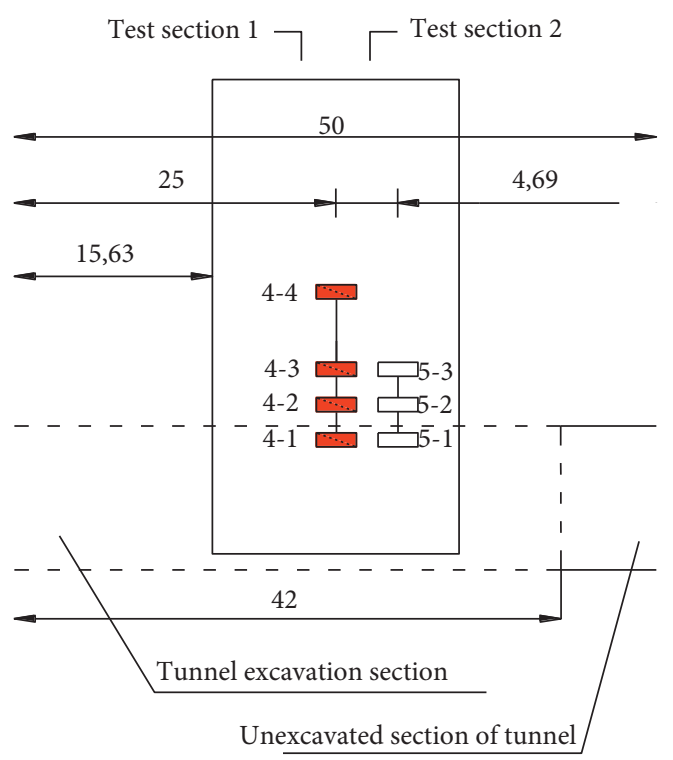

Earth pressure cell

$\because$ Pore water pressure gauge

FIGURE 7: Design of the monitoring scheme.

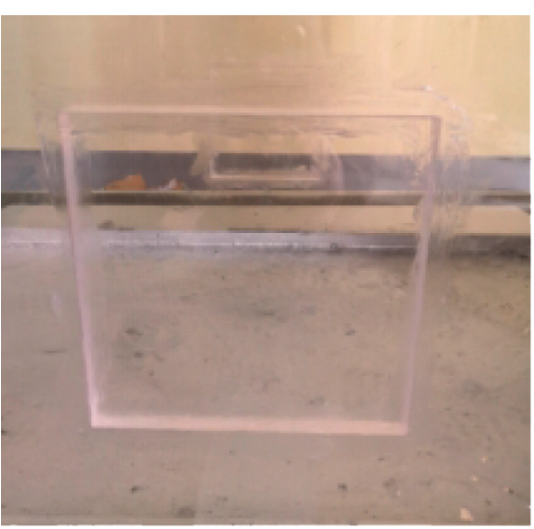

(a)

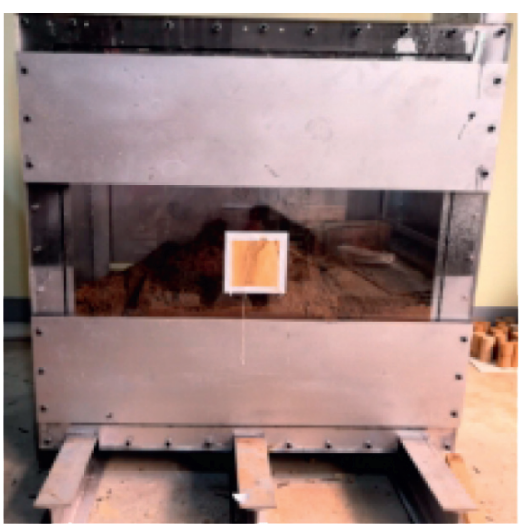

(b)

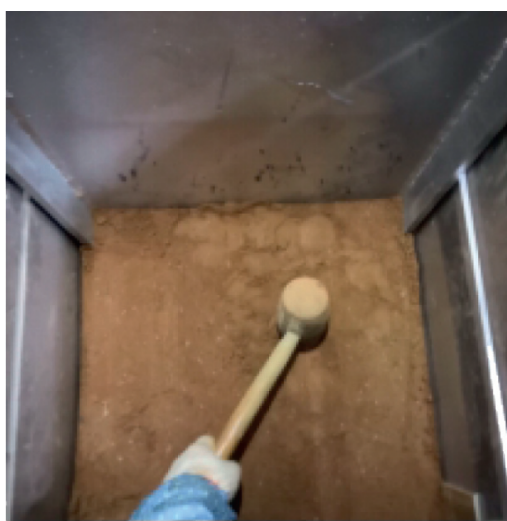

(c)

Figure 8: Continued. 


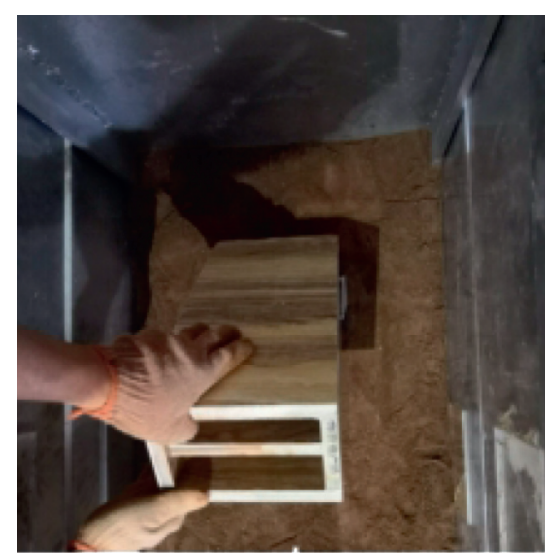

(d)

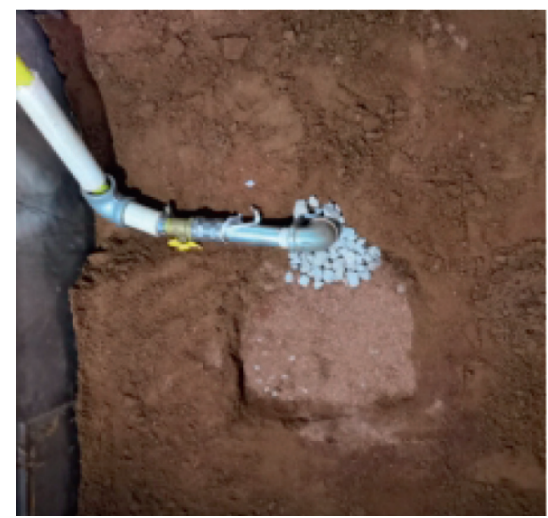

(g)

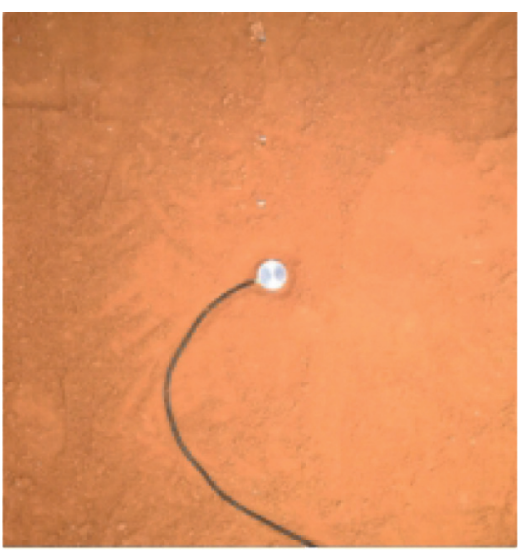

(e)

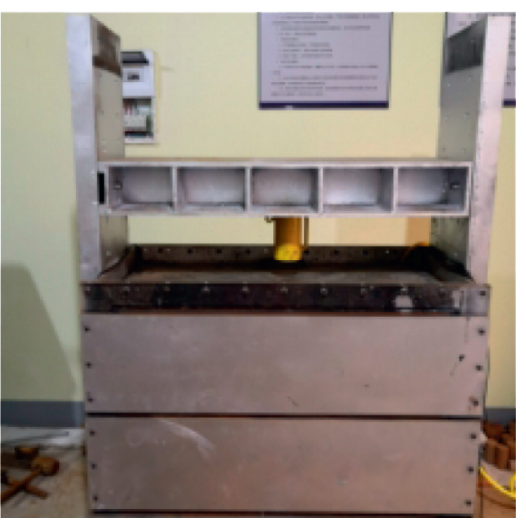

(h)

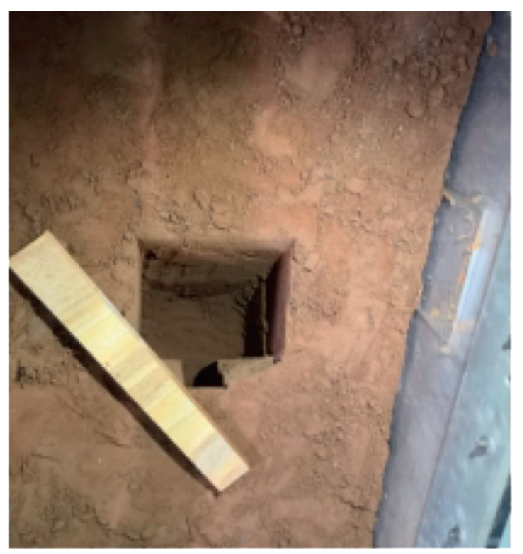

(f)

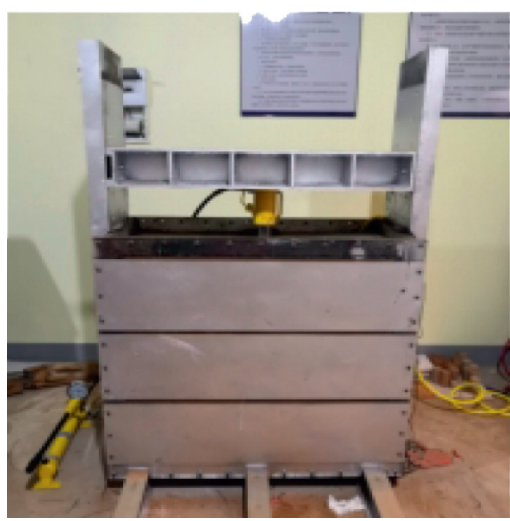

(i)

Figure 8: Model body production process. (a) Embedded glass panel. (b) Filling materials. (c) Layer compaction. (d) Mold positioning. (e) Embedded monitoring elements. (f) Molding. (g) Filling fault buried water pipe. (h) Install reaction frame and jack. (i) Hydraulic loading.

completion, put six pieces in front and back. The stiffening ribs are connected to the test frame by bolts.

(2) Screen the raw materials required for the test, weigh the screened materials according to the selected similar material ratio, and weigh $120.4 \mathrm{~kg}$ of mountain sand, $9.5 \mathrm{~kg}$ of red clay, and $7.02 \mathrm{~kg}$ of cement each time and pour them into the mixer for mixing. After stirring evenly, pour in weighed $13.1 \mathrm{~kg}$ of water and stir for about 20 minutes.

(3) Spread the mixed similar material in layers from bottom to top in the rigid test box, and then pound it manually. When the filling reaches the designed fault position, the prefabricated fault mold is positioned by tape measure, protractor, and other instruments and then continue to fill the similar material and compact the fixed mold.

(4) When the height of material filling exceeds the height of the buried monitoring element, the monitoring element is buried at the designated position, and then the similar material is backfilled into the recess and compacted. All data lines are finally led uniformly from the gap position between the pressure equalization plate and the box.
(5) When the material filling height reaches the design height of the fault, take out the mold and fill it with similar materials and gravel layers in sequence, bury the water outlet device, then continue to fill similar materials to the total design height, and scrape the top surface of the model body. After leveling, press the reaction frame and jack, place the pressure uniform plate on the top surface of the compacted and flattened model body, and finally load it to the initial ground stress step by step using a stepwise loading method.

3.8. Model Excavation and Testing. After the model was deformed and stabilized, start to excavate the tunnel. Debug the test system before excavation, remove the stiffening ribs and planks at the tunnel excavation position, use the prepared tunnel excavation control mold to draw the tunnel excavation contour line at the excavation site, and carry out the tunnel excavation (as shown in Figure 9). Excavation simultaneously collects surrounding rock stress change data.

After the tunnel excavation is completed, use the hydraulic loading system to load the water pressure. During the loading 


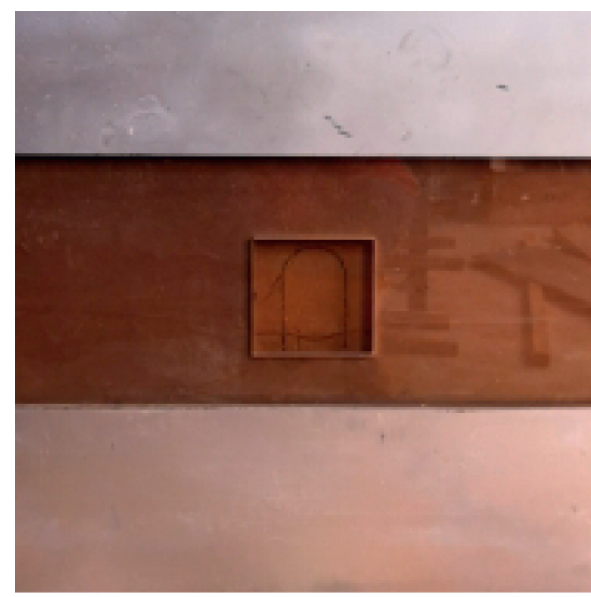

(a)

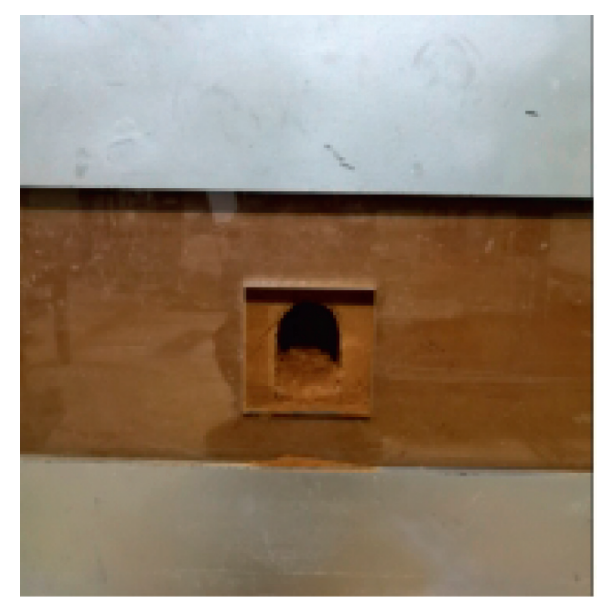

(b)

Figure 9: Basic process of model excavation. (a) Excavation contour line. (b) Tunnel excavation.

process, the changes of surrounding rock stress, seepage pressure, and other data shall be paid attention to, but the water inrush position in the tunnel and the formation process of the inrush channel shall be paid the HD shooting system record attention. A particular person shall be specially assigned for data acquisition, photography, and recording until the physical model test of water and mud inrush in the tunnel is completed.

\section{Analysis of Model Test Results}

4.1. Stress Change Law of Surrounding Rock during Excavation. Tunnel excavation will destroy the original stress balance state in the surrounding rock and cause the redistribution of the surrounding rock stress field within a specific range. As shown in Figure 10, the vertical stress of the monitoring points on the left side wall and the right-side wall of the tunnel generally showed a slight change in the initial stage of tunnel excavation, and then the stress value of each monitoring point increased significantly in the middle of the excavation and finally tended to be stable. Among them, the vertical stress values of the left- and right-side walls (1-1 monitoring points and 3-1 monitoring points) around the tunnel of the No. 1 monitoring section increased by about $42.68 \mathrm{kPa}$ and $41.25 \mathrm{kPa}$, respectively, and the arch ring around the tunnel of No. 2 monitoring section (monitoring point $5-1$ ). The vertical stress increases by approximately $21.27 \mathrm{kPa}$; the vertical stress on the right wall (monitoring point 3-2) at one time the hole diameter of the No. 1 monitoring section increases by approximately $9.49 \mathrm{kPa}$. The vertical stress on the right wall (3-3 monitoring point) increased by about $1.93 \mathrm{kPa}$, and the difference between the two was $7.56 \mathrm{kPa}$. From the above analysis, it can be seen that the tunnel excavation will cause the vertical stress of the surrounding rock at the sidewall and the arch ring to increase, and the increase is affected by the distance from the excavation contour.

4.2. Influence of Test Loading Water Pressure on the Catastrophic Evolution Characteristics of Water and Mud Inrush in Tunnels. Figure 11 shows the variation of pore water

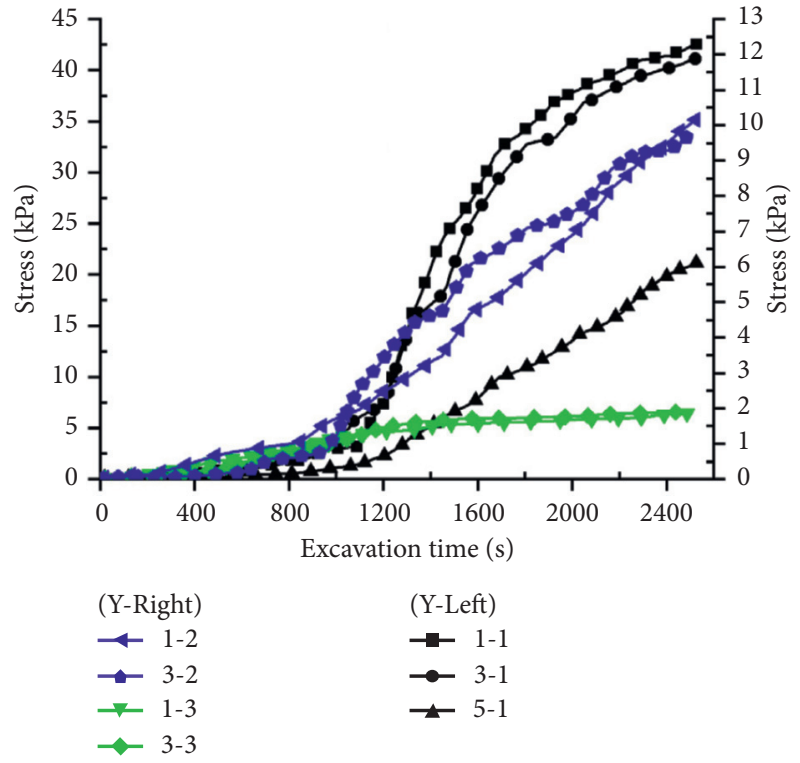

FIGURE 10: Stress change law of the measuring point during the excavation stage.

pressure at the measurement points inside the antiburst rock and fault at different hydraulic loading stages. Among them, the range of loading water pressure is $10 \sim 45 \mathrm{kPa}$. Under the same loading water pressure condition, the pore water pressure of each measuring point decreases with the vertical distance between the measuring point and the upper boundary of the fault. Taking the water pressure loading to $20 \mathrm{kPa}$ and $40 \mathrm{kPa}$ as an example, when the loading water pressure is at $20 \mathrm{kPa}$, the pore water pressure values at measuring points $4-1,4-2,4-3$, and 4-4 are, respectively, $1.78 \mathrm{kPa}, 3.65 \mathrm{kPa}$, and $14.51 \mathrm{kPa}$. And when the loading water pressure rises to $40 \mathrm{kPa}$, each pore water pressure of the measuring points changed to $5.34 \mathrm{kPa}, 8.55 \mathrm{kPa}$, $35.31 \mathrm{kPa}$, and $39.78 \mathrm{kPa}$, compared with the $20 \mathrm{kPa}$ loading water pressure, an increase of $200.00 \%, 134.24 \%, 143.35 \%$, and $102.75 \%$ year-on-year. In addition, Figure 11(d) shows 
that the pore water pressure at measurement point 4-1 was always close to the water pressure loading value at that stage at different water pressure loading stages, indicating that laying a gravel sublayer between the outlet device and the fault can effectively reduce the attenuation of the water pressure through the gravel sublayer and achieve the effect of evenly distributing the water pressure.

In different hydraulic loading stages, the pore water pressure at the same measurement point increases with the increase of loading water pressure, and when the water pressure is loaded step by step, the pore water pressure at measurement points 4-1 and 4-2 far from the gravel sublayer is nonlinear, while the measurement points 4-3 and 4-4 near the gravel sublayer are linear. When the loading water pressure increased from $10 \mathrm{kPa}$ to $45 \mathrm{kPa}$, the pore water pressure values of measurement point 4-1 and measurement point $4-2$ increased from $0.59 \mathrm{kPa}$ to $5.93 \mathrm{kPa}$ and $1.52 \mathrm{kPa}$ to $9.78 \mathrm{kPa}$, respectively, with an increase of $905.08 \%$ and $543.42 \%$, which can be seen from Figures 11(a) and 11(b) under the condition of adjacent loading water pressure; the increased value of pore water pressure at these two measuring points has noticeable difference and shows nonlinear growth. When the loading water pressure increases from $10 \mathrm{kPa}$ to $45 \mathrm{kPa}$, the pore water pressure of measurement points 4-3 and measurement point 4-4 increases from $4.37 \mathrm{kPa}$ to $40.83 \mathrm{kPa}$ and $9.76 \mathrm{kPa}$ to $44.83 \mathrm{kPa}$, respectively, with the growth rate of $834.32 \%$ and $359.32 \%$, respectively. The slope of the curves in Figures 11(c) and 11(d) shows that the pore water pressure at these two measurement points increases with the loading water pressure and shows a linear increase.

In order to study the characteristics of the hydraulic gradient changes inside the antiburst rock and fault, the local hydraulic gradient of two adjacent points can be calculated based on the pore water pressure values of two adjacent measurement points and the distance between measurement points, that is, the adjacent hydraulic gradient. The hydraulic gradient variation law inside the model body is obtained according to the pore water pressure value and the adjacent distance of each measurement point, as shown in Figure 12.

Figure 12 shows that as the vertical distance from the upper boundary of the fault increases, the hydraulic gradient inside the model body first increases and then decreases. Taking the hydraulic gradient change when the loading water pressure is $20 \mathrm{kPa}$ as an example, the vertical distance from the upper boundary of the fault is within the range of $0 \sim 12.5 \mathrm{~cm}$, and the hydraulic gradient inside the model body is 0.409 . When the distance increases to $12.5 \sim 18.38 \mathrm{~cm}$, the hydraulic gradient is 1.847 , which is a $351.59 \%$ increase compared with the hydraulic gradient in the previous range, and within the range $18.38 \sim 24.26 \mathrm{~cm}$, the hydraulic gradient becomes 0.318 , a decrease of $82.78 \%$ year-on-year. Since the hydraulic gradient inside the fault is smaller than the hydraulic gradient in the part of the rock body close to the fault, the head loss per unit length of the permeation path when the water flows through the fault is smaller than the head loss through this part of the rock body.
From the comparison of hydraulic gradients in different hydraulic loading stages, it can be seen that the vertical distance from the upper boundary of the fault is within the range of $0 \sim 12.5 \mathrm{~cm}$. With the increase of loading water pressure, the hydraulic gradient gradually decreases, at $12.5 \sim 18.38 \mathrm{~cm}$ and $18.38 \mathrm{~cm}$. In the range of $24.26 \mathrm{~cm}$, the hydraulic gradient increases with the increase of the loading water pressure. Taking the change of hydraulic gradient within the range of $0 \sim 12.5 \mathrm{~cm}$ as an example, when the loading water pressure is $10 \mathrm{kPa}, 20 \mathrm{kPa}, 30 \mathrm{kPa}$, and $40 \mathrm{kPa}$, the corresponding hydraulic gradients are 0.431, 0.409, 0.375 , and 0.358 , which are lower than the previous stage. The ranges were $5.10 \%, 8.31 \%$, and $4.53 \%$, respectively.

\subsection{Evolution Process of Water Inrush and Mud Outburst in} the Fault Fracture Zone. After the completion of tunnel excavation, the hydraulic loading stage shall be carried out. The test adopts the step-by-step pressurization method to load the water pressure, the initial water pressure is $10 \mathrm{kPa}$, and the loading water pressure of each stage is $5 \mathrm{kPa}$. In order to make the pressure water have full seepage coupling with surrounding rock materials and fault filling materials, it can be loaded to the lower water pressure only after the software monitoring data is stable. During the test, make records of seepage or water and mud inrush under different loading water pressures, and the records are shown in Table 3.

At the beginning of the hydraulic loading stage, the tunnel seepage area gradually expanded from the right arch wall to the excavated palm face, the top of the arch, the left arch wall, and other locations. When the loading water pressure was $15 \mathrm{kPa}$, water seepage occurred in the right arch wall, and as the water pressure increased during the test, the seepage area gradually expanded to the left arch wall away from the water-filled fault, and the seepage volume of the tunnel as a whole continued to increase.

When the loading water pressure rises to $40 \mathrm{kPa}$, there is a small stream of water flowing out of the arch wall on the right side of the monitoring section; when the water pressure is loaded to $45 \mathrm{kPa}$, the surrounding rock of the right arch wall falls off partially, and cracks are produced, and streams of water flow out; when the water pressure continues to increase to $50 \mathrm{kPa}$, the water gushing out from the tunnel keeps increasing, and the gushing out is a mixture of mud and sand, indicating that the surge channel gradually connected, and there are apparent precursors of water and mud inrush; when the water pressure after loading to $55 \mathrm{kPa}$, seepage instability of right arch wall occurs, the mud water mixture in the fault erupted suddenly, the water and mud inrush forms, and subsequently, the fault in the gravel was washed out by the flow of water. After a while, the water and mud inrush was stable, and the water stored in the surrounding rock began to dissipate. After the test, part of the fault filling was deposited at the bottom of the tunnel. The specific process of tunnel water and mud inrush is shown in Figure 13. 


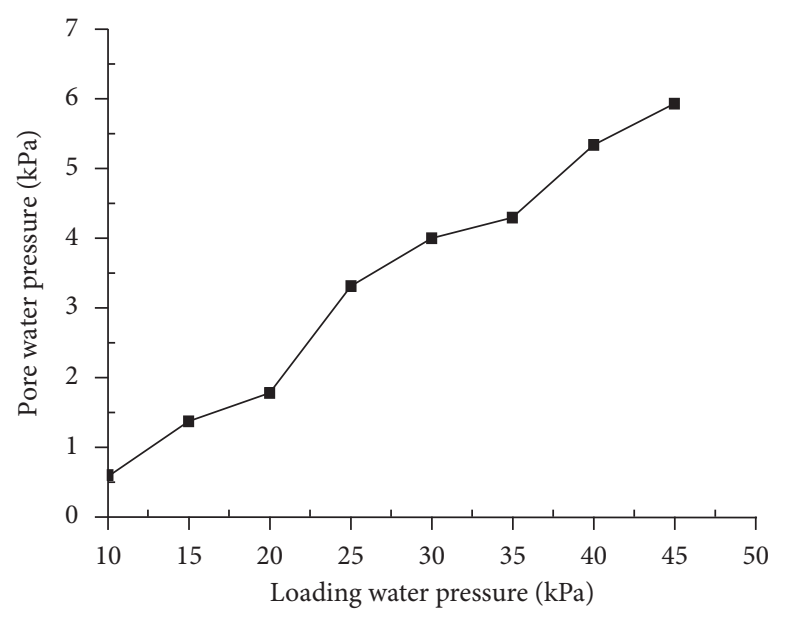

(a)

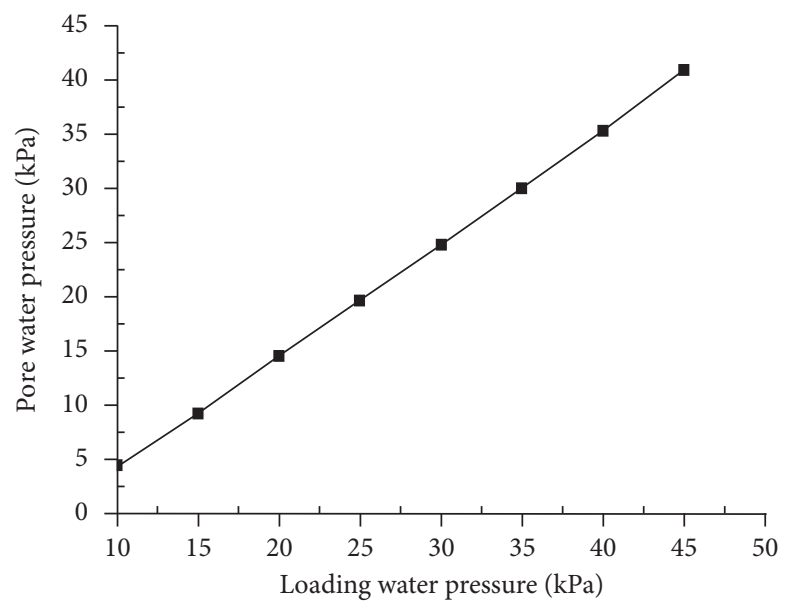

(c)

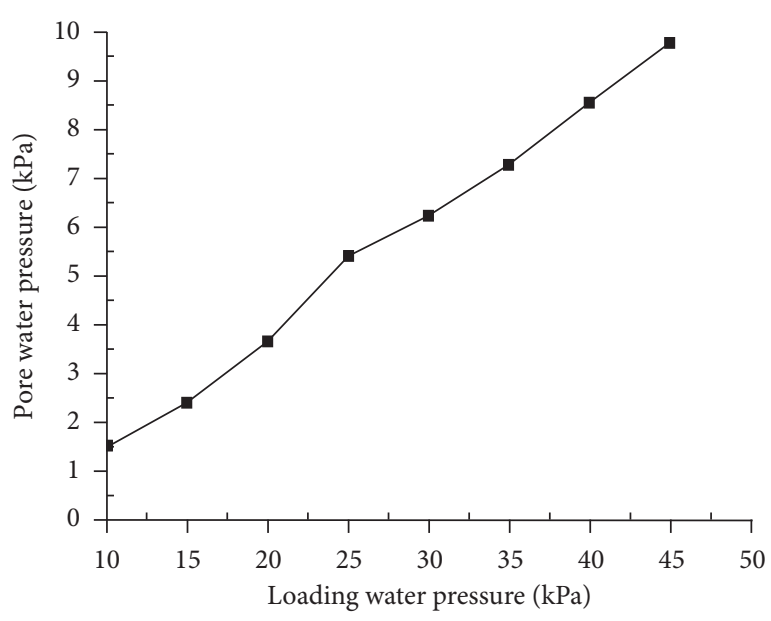

(b)

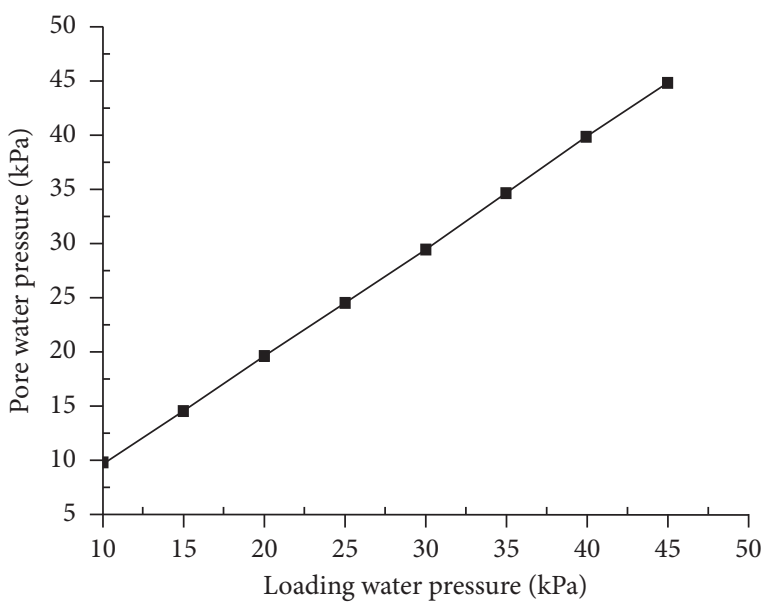

(d)

FiguRE 11: Pore water pressure variation rules at different monitoring points under different loading water pressures. (a) Monitoring point 4-1. (b) Monitoring point 4-2. (c) Monitoring point 4-3. (d) Monitoring point 4-4.

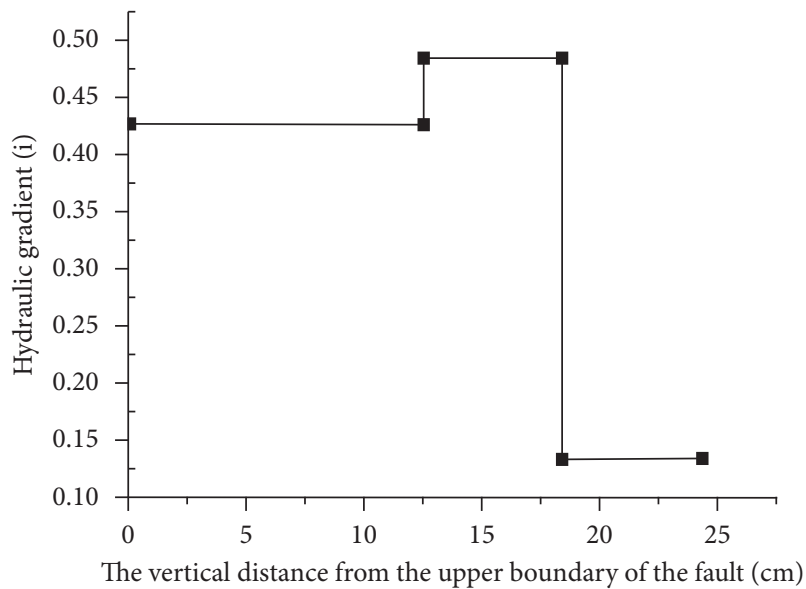

(a)

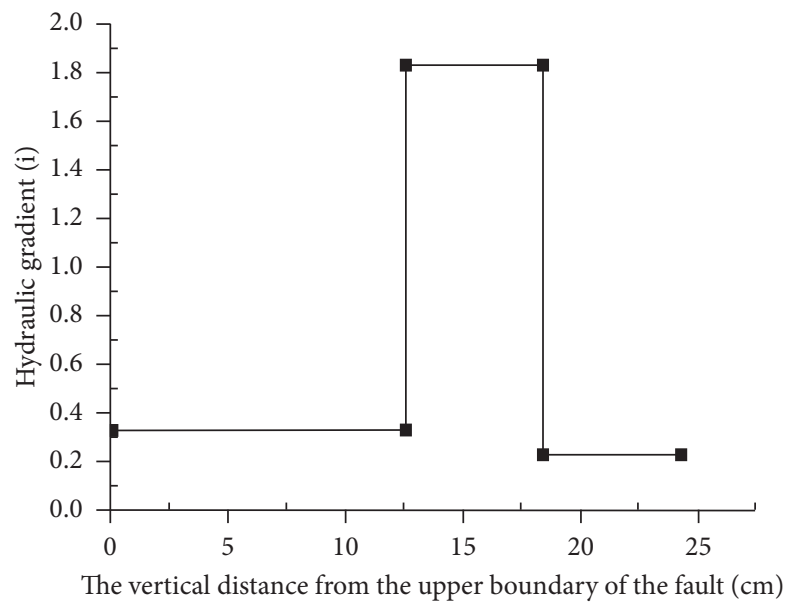

(b)

Figure 12: Continued. 


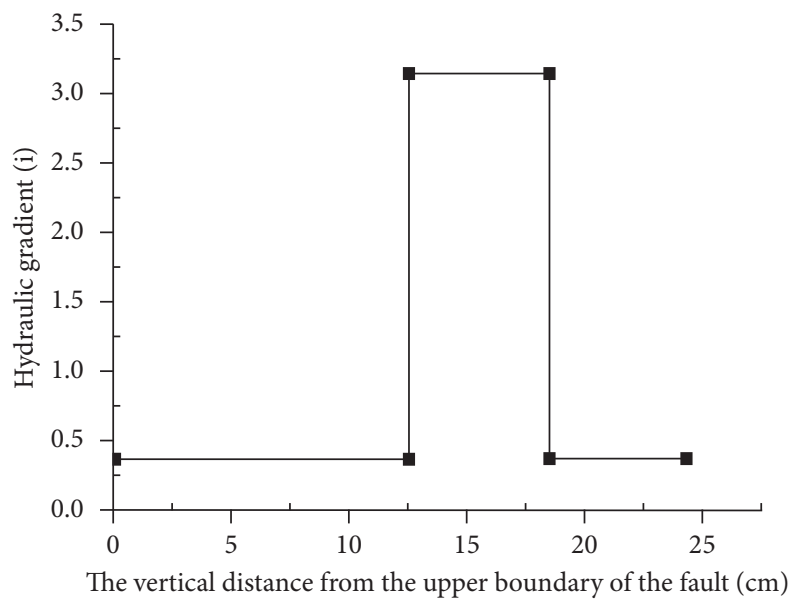

(c)

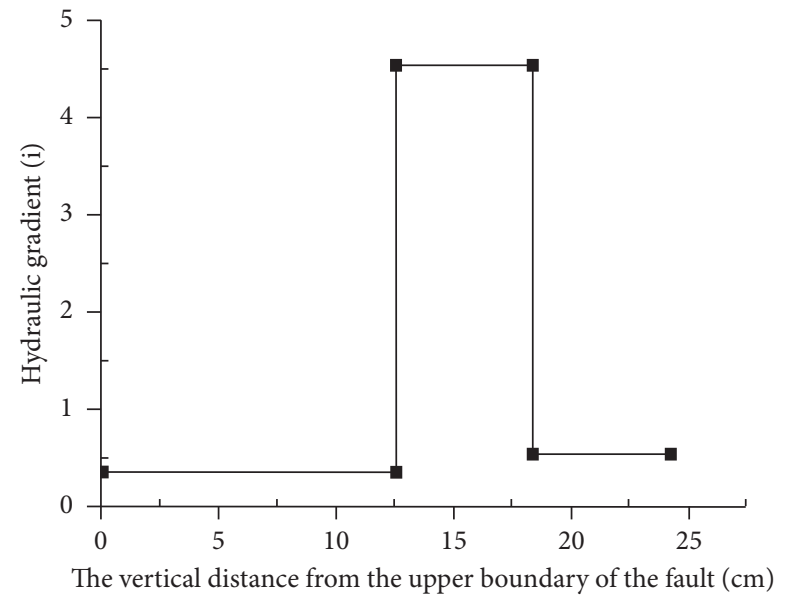

(d)

Figure 12: Hydraulic gradient under different loading water pressures. (a) Loading water pressure $10 \mathrm{kPa}$. (b) Loading water pressure $20 \mathrm{kPa}$. (c) Loading water pressure $30 \mathrm{kPa}$. (d) Loading water pressure $40 \mathrm{kPa}$.

TABLE 3: Seepage state of the tunnel under different loading water pressures.

\begin{tabular}{lcc}
\hline Loading steps & Loading water pressure/kPa & Test phenomenon record \\
\hline 0 & 10 & No obvious phenomenon \\
1 & 15 & There is a small amount of water seepage on the right arch wall \\
2 & 20 & A small amount of water flows out of the hole \\
3 & 25 & Water seepage on the vault and tunnel surface \\
4 & 30 & Water seepage in the left arch wall \\
5 & 35 & The change is not obvious, it is still water seepage from the excavation surface \\
6 & 40 & There is a small puddle of water flowing out of part of the right wall \\
7 & 45 & Cracks occurred in the arch wall on the right, and water flowed out \\
8 & 50 & Mud-water mixture flowing out \\
9 & 55 & Large amounts of water and mud \\
\hline
\end{tabular}

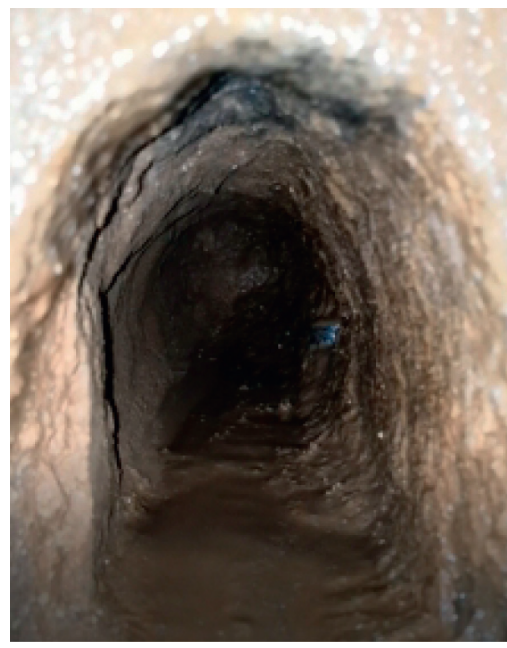

(a)

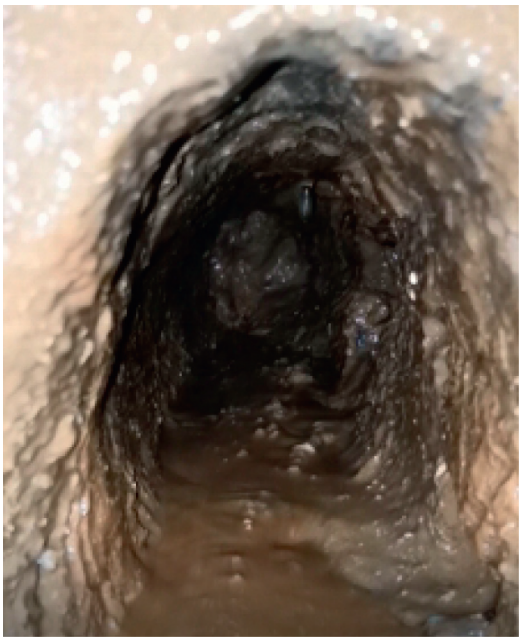

(b)

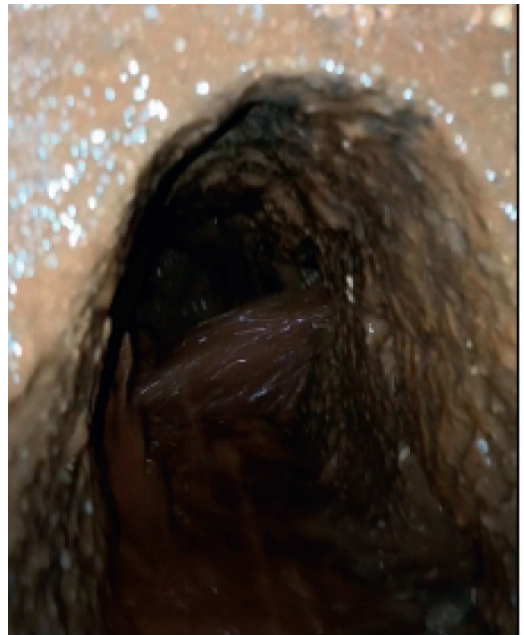

(c)

Figure 13: Continued. 


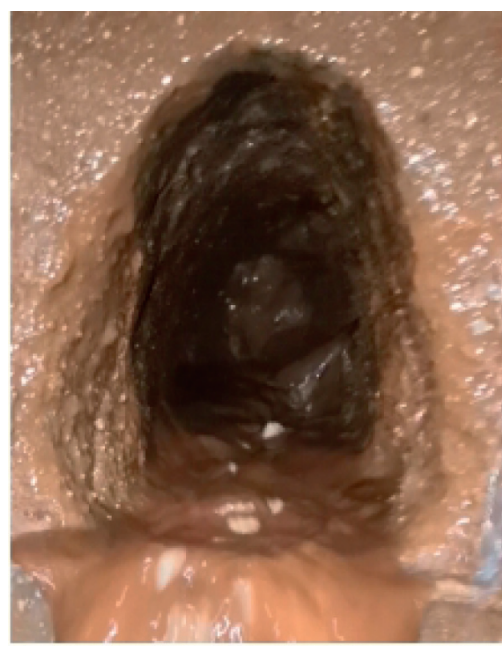

(d)

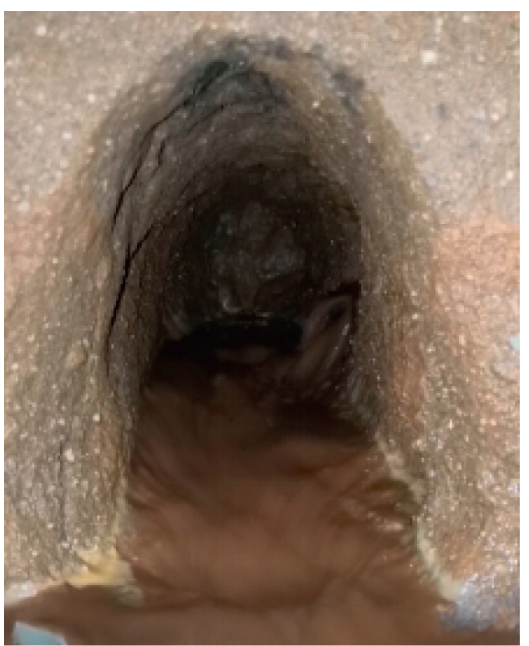

(e)

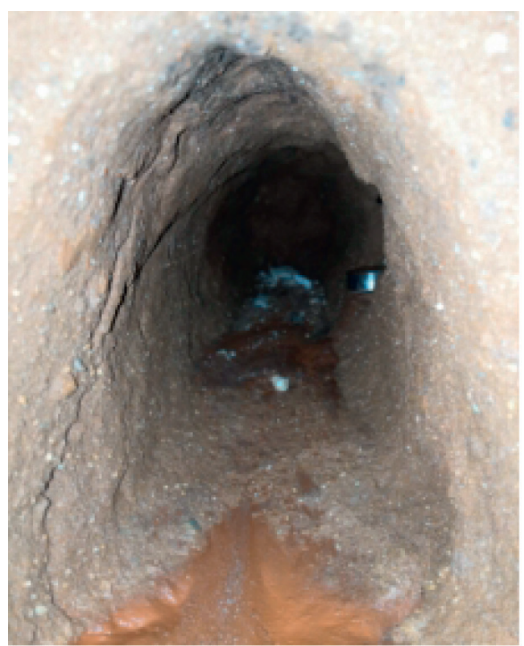

(f)

Figure 13: Catastrophic evolution process of water inrush and mud inrush in tunnel. (a) Water seepage of right arch wall. (b) The cracks produce mud-water mixture outflow. (c) Water inrush formation. (d) Mud and gravel gush out. (e) Water inrush stability. (f) End of test.

\section{Conclusions}

(1) Aiming at the significant problem of water and mud inrush in fault fracture zone during tunnel construction in mountainous plateau area, a three-dimensional visual, physical model test system suitable for fluid-solid coupling under high ground stress and high-water pressure is developed, which is composed of rigid test frame, in situ stress loading system, water pressure loading system, mud and water outburst recovery system, and multivariate information monitoring and acquisition system. It has the advantages of diversified monitoring information, good sealing, visualization, easy operation, and strong expansibility.

(2) Using the model test system, using the self-developed fluid-solid coupling similar material, a model test of water and mud inrush in the tunnel fault fracture zone is designed according to the engineering example. The data of surrounding rock stress and pore water pressure during tunnel excavation are monitored, and the essential characteristics of surrounding rock stress and deformation are mastered; the catastrophic evolution process of water and mud inrush in tunnel fault fracture zone is reproduced.

(3) In the tunnel excavation stage, the radial stress of the surrounding rock at the vault decreases due to the stress release, while the vertical stress of the surrounding rock at the sidewall increases. With the advance of the excavation face, the change of surrounding rock stress at each measuring point in the monitoring section is to maintain a stable change at first, then change sharply, and finally gradually tend to be stable. In the tunnel excavation process, the closer to the excavation contour, the more pronounced the change of surrounding rock stress is affected by excavation. In the stage of water pressure loading, the surrounding rock stress and pore water pressure at each measuring point increase first and then decrease with the increase of loading water pressure.

\section{Data Availability}

The data used to support the findings of this study are included within the article.

\section{Conflicts of Interest}

The authors declare that they have no conflicts of interest.

\section{Acknowledgments}

This study was supported and funded by the China Chile International (Regional) Cooperation and Exchange Key Projects of the National Natural Science Foundation of China (no. 41861134008), the General Projects of Yunnan Basic Research Program (no. 2018FB075), and the Key R\&D Projects in Yunnan Province (no. 202003AC100002).

\section{References}

[1] Y. Zhou, S. C. Li, L. P. Li, Q. Q. Zhang, and S. S. Shi, "New technology for fluid-solid coupling tests of underground engineering and its application in experimental simulation of water inrush in filled-type karst conduit," Chinese Journal of Geotechnical Engineering, vol. 37, no. 7, pp. 1232-1240, 2015.

[2] K. Wang, S. C. Li, Q. S. Zhang et al., "Development and application of new similar materials of surrounding rock for a solid-liquid coupling model test," Rock and Soil Mechanics, vol. 37, no. 9, pp. 2521-2533, 2016.

[3] S. C. Li, X. D. Feng, S. C. Li, L. P. Li, and G. Y. Li, "Research and development of a new similar material for solid-fluid 
coupling and its application," Chinese Journal of Rock Mechanics and Engineering, vol. 29, no. 2, pp. 281-288, 2010.

[4] A. H. Liu, S. Q. Peng, X. B. Li, and H. J. Chen, "Development and application of similar physical model experiment system for water inrush mechanism in deep mining," Chinese Journal of Rock Mechanics and Engineering, vol. 28, no. 7, pp. 13351341, 2009.

[5] J. Zhang and Z. J. Hou, "Experimental study on simulation materials for solid-liquid coupling," Chinese Journal of Rock Mechanics and Engineering, vol. 23, no. 18, pp. 3157-3161, 2004.

[6] Q. X. Huang, W. Z. Zhang, and Z. C. Hou, "Study of simulation materials of aquifuge for solid-liquid coupling," Chinese Journal of Rock Mechanics and Engineering, vol. 29, no. Supp.1, pp. 2813-2818, 2010.

[7] W. X. Li, G. Wang, W. Z. Du, P. F. Wang, J. H. Chen, and W. B. Sun, "Development and application of a true triaxial gas-solid coupling testing system for coal seepage," Rock and Soil Mechanics, vol. 37, no. 7, pp. 2109-2118, 2016.

[8] J. Xu, S. J. Peng, G. Z. Yin, Y. Q. Tao, H. W. Yang, and W. Z. Wang, "Development and application of three-axial servo-controlled seepage equipment for hot-fluid-solid coupling of coal containing methane," Chinese Journal of Rock Mechanics and Engineering, vol. 29, no. 5, pp. 907-914, 2010.

[9] J. P. Yang, W. Z. Chen, H. M. Tian, and G. J. Wu, "Development of thermo-gaseous-mechanical coupling triaxial testing system of low permeability medium and its application," Journal of rock mechanics and engineering, vol. 28, no. 12, pp. 2377-2382, 2009.

[10] G. Z. Yin, W. P. Li, J. Xu et al., "Development and application of fracturing and seepage experimental system for multiphysical field and multiphase coupling of porous media," Journal of rock mechanics and engineering, vol. 35, no. S1, pp. 2853-2861, 2016.

[11] W. M. Yang, H. Wang, X. Yang et al., "Development and application of model test system for water inrush in high- geostress and high hydraulic pressure tunnels," Journal of rock mechanics and engineering, vol. 36, no. S2, pp. 3992-4001, 2017.

[12] Q. Wang, M. He, S. Li et al., "Comparative study of model tests on automatically formed roadway and gob-side entry driving in deep coal mines," International Journal of Mining Science and Technology, vol. 31, no. 4, pp. 591-601, 2021.

[13] W. B. Sun and S. C. Zhang, "Development of floor water invasion of mining influence simulation testing system and its application," Journal of rock mechanics and engineering, vol. 34, no. S1, pp. 3274-3280, 2015.

[14] Y. L. Luo, Q. Wu, M. L. Zhan, and J. C. Sheng, "Development of seepage-erosion-stress coupling piping test apparatus and its primary application," Journal of rock mechanics and engineering, vol. 32, no. 10, pp. 2108-2114, 2013.

[15] C. He, Z. Li, S. Z. Yang, Y. W. Luo, and W. B. Yang, "Development and application on mined tunnel seepage model test system for construction and operation period," Chinese Journal of highway, vol. 30, no. 5, pp. 114-121 + 131, 2017.

[16] Q. Wang, Y. Wang, M. C. He et al., "Experimental research and application of automatically formed roadway without advance tunneling," Tunnelling and Underground Space Technology, vol. 114, p. 2021.

[17] W. Z. Zhang, "Development and application of 3D large-scale simulation experiment system of water inrush caused by collapse column," Journal of China University of mining and technology, vol. 45, no. 1, pp. 56-61, 2016.
[18] L. M. Yin, W. J. Guo, and J. T. Chen, "Development of true triaxial rock test system of coupled stress-seepage and its application," Journal of rock mechanics and engineering, vol. 33, no. S1, pp. 2820-2826, 2014.

[19] L. P. Li, S. Liu, S. C. Li et al., "Development of testing system for coupled seepage and triaxial stress measurements and its application to permeability characteristic test on filling medium," Geotechnical mechanics, vol. 38, no. 10, pp. 3053-3061, 2017.

[20] L. P. Li, Study on Catastrophe Evolution Mechanism of Karst Water Inrush and its Engineering Application of High-Risk Karst Tunnel, Shandong University, Jinan, China, 2009.

[21] C. Zhu, M. C. He, X. H. Zhang, Z. G. Tao, Q. Yin, and L. F. Li, "Nonlinear mechanical model of constant resistance and large deformation bolt and influence parameters analysis of constant resistance behavior," Rock and Soil Mechanics, vol. 42, no. 7, pp. 1911-1924, 2021.

[22] Z. Tao, Y. Shu, X. Yang, Y. Peng, Q. Chen, and H. Zhang, "Physical model test study on shear strength characteristics of slope sliding surface in Nanfen open-pit mine," International Journal of Mining Science and Technology, vol. 30, no. 3, pp. 421-429, 2020.

[23] W. S. Zhu, Q. B. Zhang, Y. Li, L. F. Sun, L. Zhang, and W. H. Zheng, "Development and application of large geomechanical model test system under true triaxial load," Journal of rock mechanics and engineering, vol. 29, no. 1, pp. 1-7, 2010.

[24] Q. S. Zhang, D. M. Wang, S. C. Li, X. Zhang, Y. H. Tan, and K. Wang, "Development and application of model test system for inrush of water and mud of tunnel in fault rupture zone," Chinese Journal of Geotechnical Engineering, vol. 39, no. 3, pp. 417-426, 2017.

[25] S. C. Li, K. Wang, L. P. Li et al., "Development and application of an extendable model test system for water inrush simulation in subsea tunnel," Chinese Journal of Rock Mechanics and Engineering, vol. 33, no. 12, pp. 2409-2418, 2014.

[26] S. C. Li, S. G. Song, L. P. Li et al., "Development on subsea tunnel model test system for solid_fluid coupling and its application," Chinese Journal of Rock Mechanics and Engineering, vol. 32, no. 5, pp. 883-890, 2013.

[27] S. C. Li, L. P. Li, S. C. Li et al., "Development and application of similar physical model test system for waler inrush of underground engineering," Journal of Mining and Safety Engineering, vol. 27, no. 3, pp. 299-304, 2010.

[28] S. C. Li, Y. Zhou, L. P. Li et al., "Development and application of a new similar material for underground engineering fluidsolid coupling model test," Chinese Journal of Rock Mechanics and Engineering, vol. 31, no. 6, pp. 1128-1137, 2012.

[29] L. Li, X. L. Rong, M. Y. Wang, H. Lu, Y. P. Xia, and Z. C. Zhang, "Development and application of 3D model test system for water inrush geohazards in long and deep tunnels," Chinese Journal of Rock Mechanics and Engineering, vol. 35, no. 3, pp. 491-497, 2016.

[30] L. Li, M. Y. Wang, P. X. Fan, Y. H. Cheng, Z. Z. Li, and H. M. Jiang, "Development of loading and unloading apparatus for model test in deep underground engineering," Geotechnical mechanics, vol. 37, no. 01, pp. 297-304, 2016.

[31] Q. Y. Zhang, W. Xiang, Y. Zhang, C. Wang, and C. C. Liu, "Development and application of ultra high pressure3D loading model test system with intelligent numerical control function," Chinese Journal of Rock Mechanics and Engineering, vol. 35, no. 8, pp. 1628-1637, 2016.

[32] X. S. Li, K. Peng, J. Peng, and D. Hou, "Experimental investigation of cyclic wetting-drying effect on mechanical 
behavior of a medium-grained sandstone," Engineering $\mathrm{Ge}$ ology, vol. 293, p. 2021.

[33] J. W. Bai, Study on Delayed Water Inrush Mechanism of Fault and Prevention and Control Key Technology in Deep Rock Mass, Shandong University, Jinan, China, 2018.

[34] Q. Yin, J. Y. Wu, C. Zhu, M. C. HE, and Q. X. Meng, "Shear mechanical responses of sandstone exposed to high temperature under constant normal stiffness boundary conditions," Geomechanics and Geophysics for Geo-Energy and Geo-Resources, vol. 7, no. 2, 2021.

[35] X. S. Li, K. Peng, J. Peng, and H. Xu, "Effect of cyclic wettingdrying treatment on strength and failure behavior of two quartz-rich sandstones under direct shear," Rock Mechanics and Rock Engineering, vol. 6, 2021.

[36] Y. C. Mo, Stability Research on High Water Pressure Filled Karst Caves Tunnel, Southwest Jiaotong Universit, Chengdu, China, 2009.

[37] R. Zhang, Z. Jiang, H. Zhou, C. Yang, and S. Xiao, "Groundwater outbursts from faults above a confined aquifer in the coal mining," Natural Hazards, vol. 71, no. 3, pp. 1861-1872, 2014.

[38] W. P. Li, Q. M. Liu, and R. H. Sun, "Theoretical and experimental study on vadose conversion of water inrush later occurred from structure broken zone," Coal Science and Technology, vol. 39, no. 11, pp. 10-13, 2011.

[39] W. H. Sui and Q. H. Dong, "Variation of pore water pressure and its precursor significance for quicksand disasters due to mining near unconsolidated formations," Chinese Journal of Rock Mechanics and Engineering, vol. 27, no. 9, pp. 1908-1916, 2008.

[40] X. Wang, z. Tan, M. Wang, M. Zhang, and H. Ming, "Theoretical and experimental study of external water pressure on tunnel lining in controlled drainage under high water level," Tunnelling and Underground Space Technology, vol. 23, no. 5, pp. 552-560, 2008.

[41] Y. Q. Hu, Y. S. Zhao, and D. Yang, "3D solid-liquid coupling experiment study into deformation destruction of coal stope," Journal of Liaoning Technical University, vol. 26, no. 4, pp. 520-523, 2007.

[42] L. Y. Yu, H. W. Jing, B. S. Xu, and Y. C. Wang, "Solid-fluid coupling analogous material test for subsea tunnel," Journal of Central South University, vol. 46, no. 3, pp. 983-990, 2015. 